Supplement of Geosci. Model Dev. Discuss., 8, 2949-2972, 2015

http://www.geosci-model-dev-discuss.net/8/2949/2015/

doi:10.5194/gmdd-8-2949-2015-supplement

(c) Author(s) 2015. CC Attribution 3.0 License.

(c) (1)

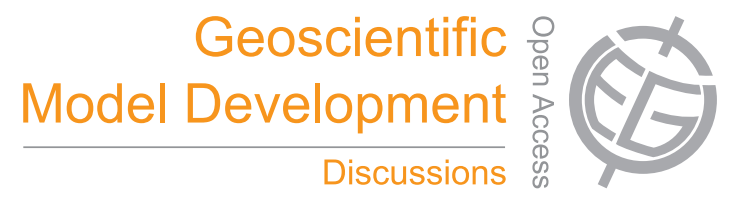

Supplement of

\title{
Increasing vertical mixing to reduce Southern Ocean deep convection in NEMO
}

\section{Heuzé et al.}

Correspondence to: C. Heuzé (c.heuze@uea.ac.uk) 


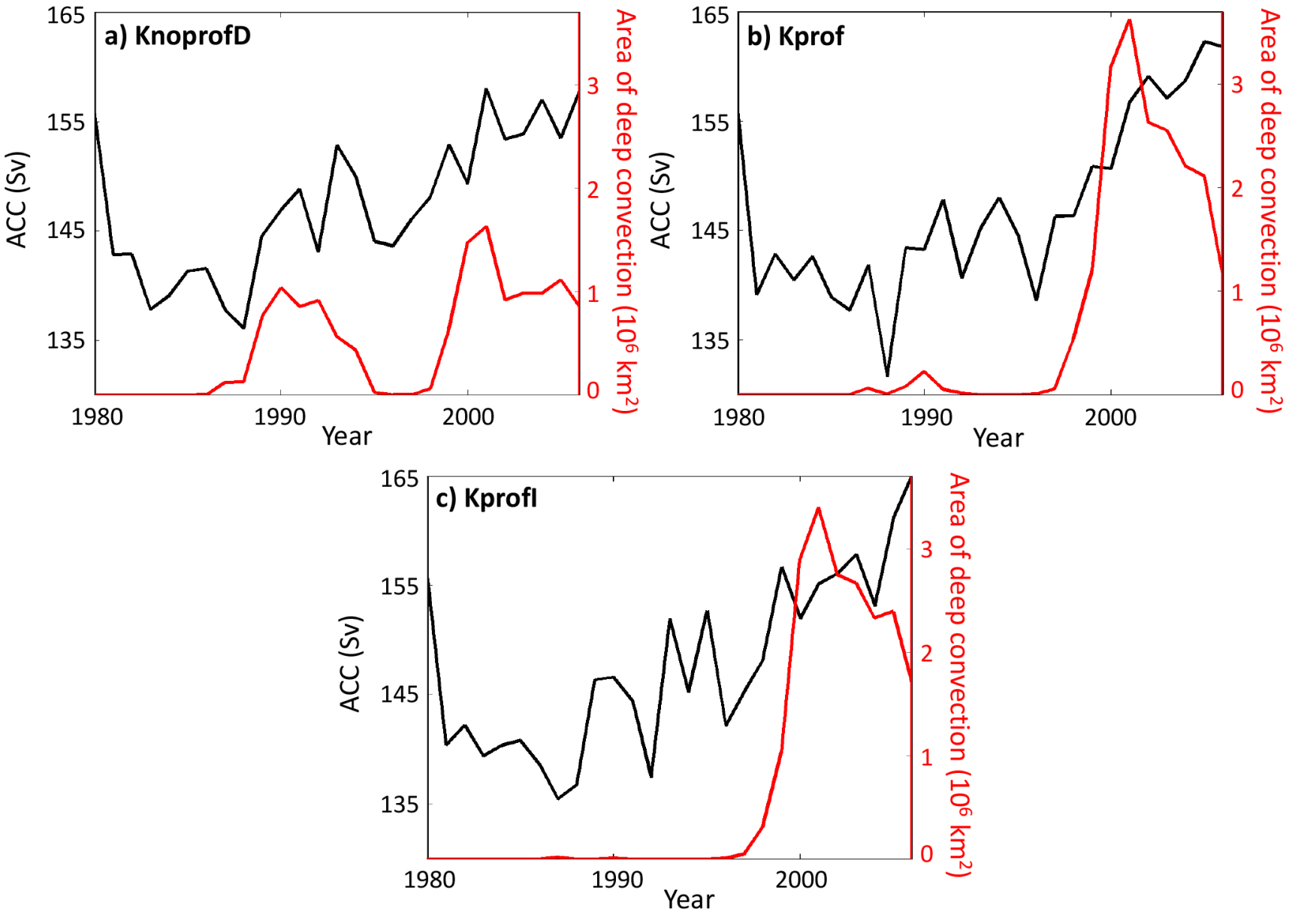

27-year time series of the annual maximum ACC (black) and annual maximum area of deep convection in the Southern Ocean (red). 